\title{
As condições de sustentabilidade, a organização e os efeitos do midiativismo no Rio de Janeiro
}

Marcelo Ernandez Macedo

Professor Associado da Faculdade de Comunicação Social da Uerj, Coordenador do Laboratório de Comunicação Dialógica (LCD/FCS/UERJ)

E-mail: marcelo.ernandez@gmail.com

Elis Carneiro da Silva

Graduanda em Ciências Sociais pelo Instituto de Ciências Sociais da Uerj. Foi bolsista

de iniciação científica pelo Laboratório de Comunicação Dialógica da FCS/UERJ

E-mail: elis_cds@hotmail.com

\section{Barbara Bandini}

Licenciatura em Artes Visuais pelo Instituto de Artes da Uerj. Colaboradora do Laboratório de Comunicação Dialógica da Uerj.

E-mail: bbgaladriel@yahoo.com.br

Resumo: Este artigo é o segundo de uma trilogia sobre midiativismo. No primeiro, recentemente publicado, são abordadas as origens e as condições sociais para formação de seus coletivos; no terceiro, será retratada a ideologia dos mesmos. Neste, o foco está centrado no funcionamento de tais grupos e em como enfrentam as dificuldades do ativismo e da luta pelos direitos humanos, o enfraquecimento das manifestações populares e a hegemonia da mídia corporativa. As redes de cooperação formadas entre os midiativistas, a busca por recursos para sustentabilidade e as disputas entre os grupos são considerados aspectos centrais para a compreensão do fenômeno do midiativismo e evidenciam sua influência na transformação nos modos hegemônicos de fazer audiovisual.

Palavras-chave: midiativismo; comunicação alternativa, comunicação independente;
Abstract: This article is the second of a trilogy about "midiativismo" (media activism). In the first one, recently published, the origins and the social conditions for the formation of its collectives are approached; in the third one, their ideology will be portrayed. Here, the focus is on the functioning of such groups, how they face the challenges of activism and the struggle for human rights, the weakening of popular manifestations, as well as the hegemony of corporate media. The networks of cooperation formed among "midiativistas", the search for resources for sustainability and the disputes between groups are central aspects to understand the phenomenon of "midiativismo", showing its influence in transforming the hegemonic means of audiovisual creation.

Keywords: media activism, alternative comunication, independent comunication. 


\section{INTRODUÇÃO}

Em um contexto de graves violações aos direitos humanos e à cidadania, o midiativismo - aqui entendido como a produção e a veiculação de audiovisual na internet por indivíduos ou grupos com identidade vinculada ao campo do jornalismo - ganha proeminência como estratégia para a oferta de representações sociais diferenciadas em relação às mídias corporativas e para a denúncia dos abusos e ilegalidades promovidos pelo Estado e por aqueles que se aproveitam de sua ausência para extorquir e ameaçar fisicamente. Os textos, fotos e vídeos publicados nas redes sociais constituem provas jurídicas contra essas ações. Ao lado da publicização dessa violência e da constituição de elementos de prova, a possibilidade de registro dessas violações significa também uma forma de proteção àqueles que se manifestam contra as mesmas. Tal proteção torna-se cada vez mais necessária diante dos abusos e ameaças que midiativistas e militantes de direitos humanos sofrem e da crescente e desmedida violência nos grandes centros urbanos, principalmente a partir do crescimento das milícias e sua associação com grupos de extermínio. No Rio de Janeiro, chegamos a um ponto agudo desse processo de "barbarização social" com a execução da vereadora Marielle Franco, que se notabilizou por denunciar as violências do Estado.

Em um primeiro artigo sobre o tema do midiativismo, apresentamos as condições sociais que permitiram o seu surgimento no Rio de Janeiro. Ao contrário da tendência de naturalizar o fenômeno, procuramos desvendar os aspectos que contribuíram para a sua existência e o perfil social dos seus integrantes. Vimos que o crescimento do midiativismo só foi possível a partir de outras experiências internacionais ocorridas num passado recente e da própria trajetória histórica da mídia independente no país; da insatisfação com as representações construídas pela mídia corporativa sobre essas violações; das próprias experiências de violências sofridas no círculo social daqueles que o adotam como estratégia e prática; e da insatisfação em relação a um Estado que cada vez mais se ausenta de suas funções sociais básicas de promoção da saúde, educação, alimentação e moradia, criando vácuos de representação política.

Mas, como efetivamente funcionam esses grupos? Que aspectos condicionam a sua permanência? Como se organizam e tomam decisões? Quais são os efeitos de sua ação? Isso é o que pretendemos responder nesse segundo artigo sobre este tema. Entendemos que a resposta a essas questões ajuda a compreender os aspectos que condicionam o desenvolvimento desse fenômeno que, como vimos, constitui-se uma das principais estratégias de proteção e denúncia na luta por direitos humanos. Em um terceiro artigo, discorreremos sobre a ideologia e os conflitos que movimentam esses grupos, completando assim um primeiro conjunto de pesquisas sobre o tema.

Assim como no primeiro artigo, partiremos de pesquisa de campo efetuada junto a esses grupos durante a realização do documentário de longa metragem Mídia em Movimento, que acompanhou o trabalho de alguns grupos de mídia independente entre o final de 2013 e o final de 2014, bem como diversas 
1.CASTELLS, Manuel. Redes de indignação e esperança: movimentos sociais na era da internet. Tradução de Carlos Alberto Medeiros. Rio de Janeiro: Zahar, 2013.

2.SOUSA, Ana Lucia Nunes de. De La Calle A La Red: Videoactvismo En El Contexto De Las Protestas En Contra Del Mundial De Fútbol En Rio De Janeiro (2014). 2017. Tese (Doutorado em Ciências da Comunicação e Jornalismo) - Universidad Autónoma de Barcelona, Barcelona, 2017.

3.MACEDO, Marcelo Ernandez; SEIDEL, A.; FERREIRA, M. O Jornal O Cidadão e os desafios para a sustentabilidade de veículos de comunicação comunitária. Comunicação \& Política, Porto Alegre, v. 31, p. 134-151, 2013..

4.MACEDO, Marcelo Ernandez. Zé Pureza: etnografia de um acampamento no norte Fluminense. 2003. Tese (Doutorado em Ciências Sociais) - Universidade Estadual do Rio de Janeiro, Rio de Janeiro, 2003. entrevistas realizadas para o mesmo. Após esse período, realizamos algumas outras entrevistas com outros indivíduos pertencentes a grupos que tiveram atuação nesse período. Em relação à pesquisa bibliográfica, destacam-se os trabalhos de Castells ${ }^{1}$, que discorre sobre as experiências recentes de midiativismo em diversos países; e a tese de doutorado de Sousa ${ }^{2}$, que analisa a atuação dos grupos de videoativismo no Rio de Janeiro nos últimos anos.

\section{CONDIÇÕES DE SUSTENTABILIDADE DOS GRUPOS DE MIDIATIVISMO}

As primeiras pesquisas do Laboratório de Comunicação Dialógica já indicavam que o ponto nevrálgico da comunicação independente são suas condições de sustentabilidade ${ }^{3}$. É muito frequente nesse universo a efemeridade de grupos diante da impossibilidade de reunir recursos capazes de garantir a continuidade dos seus projetos de comunicação. Diante da ausência de apoio do Estado e da iniciativa privada assim como as dificuldades de comercialização dos seus produtos, tal trabalho na maioria das vezes é realizado de forma voluntária. Não obstante, diante da necessidade de seus voluntários em obter recursos para a sua subsistência, muitas vezes o trabalho tende a ser paralisado, gerando descontinuidades ou mesmo o fim das iniciativas - o que acaba sendo problema comum a diversos movimentos sociais ${ }^{4}$.

O universo do midiativismo não funciona de forma muito diferente, embora a questão da obtenção de recursos por ṕparte de seus voluntários seja menos decisiva em relação à continuidade dos grupos. Ao longo da pesquisa de campo, verificamos que diversos midiativistas tiveram que paralisar suas atividades enquanto tais para dedicar-se ao próprio sustento. Um dos fundadores do coletivo Mariachi parou a sua militância para dedicar-se ao seu site para mochileiros por dificuldades financeiras; o principal midiativista do Jornal a Nova Democracia precisou voltar a vender autopeças pelo mesmo motivo, reduzindo de modo significativo as coberturas jornalísticas que realizava; um dos membros do coletivo Projetação resolveu dedicar-se ao fim dos seus estudos universitários e, junto com outro membro, abriu uma empresa de cervejas artesanais. Não obstante, em razão da maior quantidade de pessoas, de suas melhores condições financeiras e do baixo custo da produção para veiculação na internet, quando comparado aos veículos de comunicação comunitária (principalmente jornais e rádios), muitas vezes essas saídas não determinaram a paralisação do projeto como um todo, mas sim o seu enfraquecimento. Portanto, no caso do midiativismo, embora siga sendo uma questão bastante relevante, a dificuldade de recursos não explica, sozinha, a efemeridade dos projetos.

Ao lado dessa dificuldade, a repressão policial e o fim do ciclo de mobilizações após os Jogos Olímpicos de 2016 no Rio de Janeiro aparecem como aspectos que possam ser mais relevantes para explicar a descontinuidade do trabalho. Na verdade, nos parece que o mais correto seja dizer que estas 
condições sociais se conjugam para gerar tendências de paralisação ou extinção das atividades midiativistas.

Conforme sabemos ${ }^{5}$, diversos grupos de midiativismo surgiram na esteira das mobilizações iniciadas no início de 2013, que tiveram o seu ápice em meados daquele ano e duraram até a Copa do Mundo de 2014; dentre os grupos pesquisados, podemos citar como exemplos os coletivos Projetação e Mariachi. $\mathrm{Na}$ medida que este ciclo de mobilizações foi freado, perdeu-se em grande medida o sentido da atuação destes grupos. Em um contexto de dificuldades econômicas. em que diversos membros sentem a necessidade de direcionar esforços para o seu próprio sustento, a tendência foi a dispersão e a paralisação do trabalho de alguns destes grupos ou, no mínimo, a drástica redução de suas atividades, como foi o caso do coletivo Mariachi.

Outro caso que ilustra muito bem esse argumento é a trajetória do coletivo Projetação. No início, a manutenção do coletivo dava-se por meio de contribuições dos próprios membros e os equipamentos utilizados eram emprestados. Na medida que as mobilizações se intensificaram e o trabalho do coletivo tornou-se mais visível, eles organizaram um crowdfunding para arrecadar recursos para a compra de equipamentos próprios. Em um mês de campanha na internet, foi alcançada a meta de 20 mil reais, que serviu para adquirir grande parte do aparato necessário para a projeção de frases e imagens durante as manifestações, foco da atuação desse grupo. Na medida que o ciclo de manifestações estancou, o grupo ainda permaneceu um tempo dirigindo um cineclube até que, com a dispersão de seus membros mais ativos, que precisaram dedicar seu tempo ao desenvolvimento de suas carreiras profissionais, o coletivo paralisou suas atividades.

O depoimento abaixo de um dos integrantes do coletivo Mariachi também ilustra o nosso argumento e acrescenta mais um elemento às dificuldades de sustentabilidade do midiativismo, relacionado ao recrudescimento das manifestações: a repressão policial.

O começo de 2015 é uma época que os grupos de mídia especialmente no Rio, estão tendo que se reinventar, porque o que houve em 2013 é que tinham muitos atos e essas pessoas que participavam dos atos assistiam ao material que a gente publicava na internet. Hoje com toda a repressão do Estado a gente tem aí 23 perseguidos políticos e 4 pessoas presas em função das manifestações. O número de pessoas na rua diminuiu muito e o número de pessoas assistindo ou lendo o material que a gente faz acaba contraindo um pouco (informação verbal) ${ }^{6}$.

Um dos membros do Jornal A Nova Democracia ressaltou que os protestos foram esvaziados por dois motivos. Em primeiro lugar, por uma repressão gigantesca. Isso fez com que, aos poucos, as manifestações reunissem mais policiais do que manifestantes, além da presença de infiltrados e policiais à paisana. Em segundo lugar, a mídia hegemônica fez uma campanha maciça para desmoralizar os protestos, agravada com a morte do cinegrafista da Rede Bandeirantes, Santiago Andrade. Dessa forma, o cenário perfeito para a criminalização completa dos movimentos estava montado. Isso nos leva a concluir

5.MACEDO, Marcelo Ernandez; SILVA, Flávio; CARDOSO, Alessandra. A formação de grupos de midiativismo no Rio de Janeiro. ALCEU, Rio de Janeiro, v.18, n.35, p.94-113, jul./dez. 2017

6.Membro do coletivo Mariachi. Entrevista cedida aos autores da pesquisa. 
que a repressão que os midiativistas enfrentaram estabeleceu a sensação de risco permanente, exigindo tanto esforço físico, como resistência psicológica. E, pensando no cidadão comum que se manifesta nas ruas, a repressão policial exagerada constituiu uma ameaça, havendo um refluxo nas mobilizações e, com isso, o trabalho midiativista perdeu sua principal motivação.

\section{MODOS DE FUNCIONAMENTO, TOMADA DE DECISÕES E RELAÇÕES ENTRE OS GRUPOS}

Desde 2013, quando o fenômeno do midiativismo ganha expressão no Rio de Janeiro, a sua principal forma de atuação é a cobertura jornalística de eventos com rápida veiculação na internet, quando esta cobertura não é transmitida ao vivo por meio de streaming. Para competir com a mídia corporativa e garantir a atualidade da notícia, é necessário editar o registro produzido rapidamente e lançá-lo na rede. O trabalho de edição começa logo após a realização dos eventos, em geral manifestações políticas, podendo ocupar toda a madrugada para que, no máximo, no dia seguinte os vídeos possam ser veiculados.

Nessa prática, merece ser ressaltada a formação de redes de midiativismo entre grupos parceiros. Ao longo das manifestações de junho de 2013, grupos foram surgindo e, a partir do contato constante durante as manifestações, os midiativistas se conheceram, formaram laços de amizade e, aos poucos, passaram a cooperar por meio da troca de informações, da troca de proteção física e equipamentos nos atos e do compartilhamento de publicações. Assim, formaram-se redes dentro de cada espectro político. Havia contato permanente entre os diversos grupos, como podemos ver por meio do depoimento de um midiativista recolhido da tese de Sousa:

No princípio, eu filmava sozinha. Não conhecia ninguém. Uma vez encontrei um velho amigo em um dos protestos. Ele também estava filmando. E logo fui conhecendo a todos e todas. Depois começou essa dinâmica que todos começaram a se conhecer, e, cada vez que havia uma ação, as pessoas se conectavam por mensagens de telefone ou do Facebook. Então, este grande grupo, que era de umas 30 pessoas, foi se transformando quase em uma instituição. ${ }^{7}$

A internet foi a facilitadora dessa rede. Por meio dela, os midiativistas criaram suas plataformas, marcavam reuniões presenciais, mantinham-se informados sobre as passeatas, organizavam-se, trocavam informações e compartilhavam suas publicações entre si e com o mundo. Mas, a rede estendia-se para além da internet. As reuniões presenciais fortaleciam o objetivo. Nelas, eles discutiam as passeatas, como se organizariam no dia, e quais seriam as necessidades. Durante os protestos; agiam em conjunto e em grupo buscavam as melhores imagens, atuando em bloco para protegerem-se. Eles distinguiam-se dos outros manifestantes pelo uso de equipamentos de proteção: botas, coletes, máscaras, entre outros. Nesse segundo momento, o ato de filmar tornou-se uma forma de proteção contra os abusos e violência por parte dos policiais. Essa aproximação corporal estimulou os laços de amizade entre eles. 
Espaços de convivência, manifestações, ações audiovisuais nas comunidades, fóruns, reuniões e oficinas de formação e diálogo. Estas ações - realizadas em comunidades, ocupações e espaços de convivências - tinham a finalidade de esclarecer a população sobre o que estava acontecendo e promover o próprio reconhecimento social sobre o valor do trabalho destes grupos. "Outra coisa que estamos fazendo ultimamente é um trabalho de formação mais direta. A gente está dentro das ocupações de escolas promovendo também oficinas" (informação verbal) ${ }^{8}$. A partir dos fóruns e reuniões que se decidia tudo, analisa-se o que precisava ser feito e eram tomadas medidas para sanar seus déficits, como a capacitação para atuar nas diversas tarefas necessárias.

As reuniões de preparação para as passeatas duravam horas e podiam ser realizadas até mesmo dias antes. Cada participante usava um crachá com a identificação do coletivo. Para os trabalhos mais cansativos, como o de edição, alguns grupos realizavam festas para editar os vídeos, onde todos conversavam sobre o tema e tomavam parte do trabalho em um ambiente descontraído.

$\mathrm{Na}$ maioria dos grupos as decisões são tomadas de forma democrática, em votações onde prevalece o desejo da maioria presente a cada momento. No entanto, cresce o número de grupos que tomam suas decisões baseadas no consenso. Em outras palavras, nestes grupos uma ação só é realizada quando há acordo integral entre seus membros. Como o contexto de atuação em geral é de urgência, devido à necessidade de rápida veiculação das informações, aqueles que estão disponíveis no momento tomam as decisões necessárias. Em resumo, não há um comando centralizado; as tarefas são feitas por capacidade, necessidade, vontade e disponibilidade dos membros.

Embora haja em grande medida convergência de objetivos no campo do midiativismo e, como vimos, cooperação entre diversos grupos, essa configuração ${ }^{9}$ não é isenta de disputas, que, vale ressaltar, tem relações com aquelas verificadas nos partidos políticos da esquerda brasileira e em correntes ideológicas destes partidos. Uma primeira e clara divisão ocorre entre o maior, mais bem estruturados e reconhecido grupo de midiativismo brasileiro e boa parte dos demais grupos, sendo boa parte destes formados a partir das manifestações de junho de 2013. Essa divisão traduz a disputas na esquerda brasileira entre os petistas e aqueles que discordam das estratégias e alianças desenvolvidos por este partido ao longo dos seus 14 anos à frente do governo federal. Em outras palavras, trata-se de uma disputa entre reformadores, aqueles que utilizam estratégias mais conciliatórias e moderadas em nome da governabilidade e revolucionários, que não estão dispostos a fazer concessões nas disputas entre classes, compreendem o sistema político como uma farsa, pregam o voto nulo e acreditam na ação direta como única via possível para a transformação social em um jogo que consideram de cartas marcadas.

Os grupos com essa perspectiva "revolucionária" acusam o grupo "reformador" de ser beneficiado em editais públicos promovidos pelos governos petistas e de não adotarem modelos de gestão e práticas efetivamente "horizontais", democráticas, ao contrário do que pregam. Por sua vez, este grupo acusa os "revolucionários"

8. Membro do coletivo Linhas de Fuga. Entrevista cedida aos autores da pesquisa.

9.ELIAS, Norbert. Escritos e ensaios: 1. Estado, processo, opinião pública. Organizado por Federico Neiburg; Leopoldo Waizbort. Rio de Janeiro: Zahar, 2006. 
de fazerem uma leitura rasa do cenário político brasileiro, sendo incapazes de compreender a complexidade das correlações de forças envolvidas. O seguinte depoimento de um dos membros de um dos grupos da ala "revolucionária" traduz essa divisão dentro do midiativismo:

Hoje temos os PIGs: o PT chama do Partido da Imprensa Golpista. Seria essa mídia corporativa que tem interesses econômicos por trás da notícia que ela comercializa (SBT, Globo, Bandeirantes...). Você também tem o outro PIG que é o Partido da Imprensa Governista, que seriam o partido dos blogueiros sujos: Conversa Fiada, Pragmatismo Politico e Carta Capital, que são projetos de mídia alinhados com o governismo do Partido dos Trabalhadores. Então, correndo pela periferia, você tem a mídia que você chama de livre, que seria a gente, que não tem nenhum apoio econômico ou quando tem é muito irrisório, ou seja, a gente não se sente pautado por ninguém a não ser nós mesmos e nossas próprias ideias (informação verbal). ${ }^{10}$

Fica clara a divisão estabelecida dentro midiativismo entre os adeptos do PT e aqueles que se consideram de fato "livres", "independentes". Fica nítido também que estes são os predicados em disputa: quem tem autonomia? Quem é verdadeiramente independente do poder econômico? Quem é livre? Tais são as qualidades que estão em disputa. Vejamos a análise de um representante de um grupo acusado de alinhamento ao PT.

Passou a Copa do Mundo a gente vai entrar num ciclo que não tem como não se posicionar. E aí parte dos coletivos de midiativistas muitas vezes acaba fazendo escolhas e tem dificuldade mesmo de fazer o enfrentamento num outro nível, num outro campo, de se posicionar, de sair de cima do muro e assumir uma parte dentre as várias contradições que você tem no jogo político. Porque, cara, quando você faz uma... porque a gente vive num modelo representativo, então a gente não pode esperar que a nossa representação vai ser reflexo da nossa imagem e semelhança. Sempre vai ter discordância, alguma contradição com aquele campo que você escolhe e se ausentar desse processo de disputa simbólica de narrativas políticas acaba sendo mais nocivo do que ter a disposição para fazer o enfrentamento diante das suas posições. Então acho que parte do midiativismo enfrentou essa duas dificuldades: a dificuldade de se manter, de continuar fazendo as coisas que faz tendo estímulo pra se inserir nos campos de disputa de imaginário, como também de assumir posições e lidar com as contradições que isso acarreta (informação verbal). ${ }^{11}$

O que está em jogo neste discurso é o posicionamento diante da disputa eleitoral de 2014. Quando o autor do depoimento fala em ausentar-se do processo de disputa simbólica está criticando o posicionamento de parte significativa dos midiativistas que, alinhados aos movimentos anarquistas, pregaram o voto nulo.

As disputas entre os midiativistas não se restringem a essa dicotomia. Dentro da vertente que reivindica para si o status de maior independência, as disputas são também acirradas. Não é raro na internet, em postagens no

10.Entrevista cedida aos autores da pesquisa.

11.Entrevista cedida aos autores da pesquisa.
Facebook, ver trocas de acusações e xingamentos entre componentes destes grupos. Porém, este tema não será aprofundado, já que não é o nosso objetivo por ora. No terceiro artigo da trilogia que este artigo faz parte, 
serão exploradas as disputas ideológicas entre os grupos. Mas, quisemos aqui evidenciar que estas disputas condicionam o funcionamento dos grupos ao promoverem alianças e, principalmente, cisões. Tais cisões, ao fragmentar a rede midiativista, elemento fundamental para as mobilizações sociais recentes em outros países, dificultam as lutas contra aqueles que de fato deveriam ser os únicos inimigos políticos: o Estado repressor e a mídia corporativa que o sustenta.

\section{EFEITOS DO MIDIATIVISMO NO CAMPO DA COMUNICAÇÃO}

Mas, quais os impactos da atuação dos grupos de midiativismo no campo da comunicação? Como as novas possibilidades de produção, distribuição e circulação afetaram o campo como um todo e, principalmente, as mídias corporativas? Como o midiativismo afetou a mobilização nos movimentos sociais?

Estamos cientes que é cedo para responder a essas questões, já que as transformações sobre as quais estamos falando estão em curso, sendo ainda difícil oferecer respostas precisas. Mas, podemos observar desde já alguns direcionamentos. Em relação à mídia corporativa, fica claro que estas precisaram adaptar suas estratégias ao novo cenário. Diante do enfrentamento com o midiativismo, os grupos de mídia hegemônicos viram reduzido o espaço para distorções ou invenções de fatos em manifestações que não aconteceram, pois sabem que podem ser desmentidos publicamente, como ocorreu em algumas situações. $\mathrm{O}$ caso mais emblemático e referenciado pelos midiativistas foi o de Bruno, acusado de atirar um artefato explosivo em direção aos policiais que impediam que uma manifestação se aproximasse do Palácio Guanabara, no Rio de Janeiro, onde o Papa Francisco reunia-se com autoridades em sua última visita ao país. Em cerca de 24 horas, houve um mutirão entre os midiativistas com o objetivo de obter imagens que provassem que o artefato não partira de Bruno, mas sim de um policial infiltrado. Os midiativistas alcançaram o objetivo e reuniram imagens que, expostas na internet, obrigaram a Rede Globo a rever a acusação e admitir que foi a própria polícia a lançar o artefato. Dessa maneira, fica evidente que o espaço para distorções se reduziu, precisando os veículos de massa serem mais cautelosos na criminalização dos movimentos sociais para não perderem a sua já abalada credibilidade.

Outra adaptação refere-se ao estilo de abordagem adotado. Usualmente, a imprensa brasileira não costuma oferecer distintas visões ou versões sobre os fatos noticiados. Toma-se a fala de autoridades, muitas vezes as policiais, como verdade absoluta, dado o compromisso de, acima de tudo, custe o que custar, manter a ordem pública. Isso costumava ser produzido por meio de visões distanciadas dos fatos em si, produzidas em helicópteros e/ou gabinetes, sem a necessária imersão investigativa nos locais onde estes ocorrem. O midiativismo, ao fazer-se presente no calor dos acontecimentos com narrativas ao vivo e plurais, 
impôs à mídia novos padrões de veracidade. Além de trabalhar de helicópteros e da presença nos gabinetes, a mídia corporativa precisou desenvolver estratégias para camuflar a sua falta de proximidade com os fatos. Seja infiltrando repórteres não identificados em manifestações, seja exibindo indevidamente e sem autorização imagens dos próprios grupos de midiativismo, o fato é que a mídia corporativa viu-se obrigada a adotar essa nova estética do real ou fingir que a está adotando, simulando proximidade para legitimar as distorções. Um dos midiativistas mais atuantes nas manifestações de junho comenta o uso indevido de imagens por parte dos grandes veículos de comunicação:

A gente tem na mão do advogado que está cuidando desse lance pra gente de onze a quinze ações judiciais contra empresas de televisão devido indevido ao uso de material nosso; e a gente tem $99 \%$ de chances de ganhar grandes indenizações por conta dessas cópias. Porque a coisa é descarada, eles nem ligam pra pedir autorização. Publicam o material, apagam a nossa logo e ainda botam a deles em cima. Ou então ligam, pedem autorização e, diante de um "não", usam mesmo assim. A gente só autoriza quando é um material que não tem como distorcer... (informação verbal) ${ }^{12}$

Nos cálculos dos grandes veículos, parece que o preço das possíveis indenizações pelo uso indevido de imagens é compensado pelas vantagens obtidas a partir da distorção de determinados eventos, considerados chaves na correlação de forças políticas. Ao usarem indevidamente as imagens de grupos midiativistas, também parecem ter em vista a possibilidade de impunidade quanto a esse crime.

Por outro lado, os midiativistas são afetados em seu cotidiano pelas disfunções da mídia corporativa. Vejamos outro depoimento do mesmo midiativista acima:

Nessas coberturas de favela, por exemplo, a gente sofre as consequências desse trabalho sujo que essas empresas fazem. Nesse caso do Diego a gente foi... ele foi assassinado no domingo e na segunda a gente foi na casa dele conversar com a avó dele. O irmão dele, nós fomos extremamente hostilizados pelo irmão dele enquanto entrevistávamos a avó dele; gritando que a gente era Tim Lopes, que a gente era fechado com a polícia, que imprensa nenhuma prestava, que tinha tudo que morrer, que é imprensa policial, que é dedo duro e tal. Nós somos a exceção da regra, então a gente está sujeito a esse tipo de julgamento, a gente está sujeito a esse tipo de problema. Tivemos que sair de lá correndo. Vai que aquela gritaria dele virasse um furdúncio e outras pessoas resolvessem hostilizar a gente também. (informação verbal) ${ }^{13}$

12.Entrevista cedida aos autores da pesquisa.

13.Entrevista cedida aos autores da pesquisa.

14.JENKINS, Henry. Cultura da Convergência. São Paulo: Aleph, 2008.

15.LÉVY, Pierre. Cibercultura. São Paulo: Editora $34,1999$.
Portanto, há vezes que os estigmas negativos adquiridos pela mídia corporativa, diante das dificuldades no reconhecimento da diferenciação no campo, acabam sendo transmitidos para o midiativismo, condicionando o seu funcionamento.

No que se refere ao impacto do midiativismo sobre a mobilização social, as primeiras pesquisas direcionadas especificamente para essa questão apontam resultados diferentes daqueles propostos pela maioria dos teóricos que visualizaram nas novas tecnologias da informação a chave para a participação social e a democratização das sociedades. Autores como Jenkins ${ }^{14}$ e Levy ${ }^{15}$ acreditaram 
que as tecnologias da informação e comunicação (TIC) e a cibercultura a estas associada, ao permitirem a possibilidade de produção e veiculação de informação a baixo custo, promoveriam direito à expressão e, consequentemente, equidade social na comunicação e nas esferas da vida reclamadas a partir desta. Tais autores parecem desprezar uma série de condições sociais anteriores à utilização das TIC e subjacentes à mesma.

Em primeiro lugar, é preciso ressaltar que o acesso às TIC ainda é limitado em países ao sul da linha do Equador, tais como o Brasil, onde somente $64,7 \%$ das pessoas tem acesso à internet ${ }^{16}$. Outra questão refere-se ao fato de as redes sociais estarem sob o controle de empresas que, com seus algoritmos, restringem as possibilidades de comunicação pela rede. Ao final, aqueles que tem acesso à internet tendem a produzir ou reproduzir informações dentro de um círculo limitado de pessoas, as quais em geral tem visões próximas entre si. São as chamadas "bolhas" da internet.

Em um estudo sobre as formas de participação nas redes sociais, Villi e Matikainem ${ }^{17}$ as classificam em dois tipos, estabelecendo um continuum entre dois extremos. De um lado, haveria as formas de participação explícita, que se referem à produção de conteúdo audiovisual para publicação na rede (que se confunde com o conceito de midiativismo que adotamos e estamos trabalhando aqui). Assim, fotografar ou filmar um ato social, produzir um texto sobre o mesmo e publicar combinações disso na rede estariam no extremo da mais significativa participação (explícita). A participação implícita refere-se à utilização da rede sem produção de conteúdo, cujo extremo estaria na simples visualização de conteúdos. Entre estes dois extremos estariam as curtidas, os comentários e os compartilhamentos, sendo estes dois últimos possíveis com ou sem o acréscimo de informações. Parece relevante que tais comentários e análises aos materiais postados possam significar a produção de debates qualificados sobre os conteúdos introduzidos na rede, promovendo a reflexão sobre os fenômenos políticos e, consequentemente, a refundação da esfera pública e da opinião pública, conforme sugeridas pelos autores mais otimistas. Não obstante, ao lado das limitações de acesso e circulação de informações na rede já apontadas, algumas pesquisas indicam que esse otimismo talvez precise ser revisto.

Sousa $^{18}$, em sua tese de doutorado sobre o midiativismo, analisou a participação social em notícias geradas pelos midiativistas brasileiros no contexto da Copa do Mundo de 2014. Utilizando o modelo de Carpentier ${ }^{19}$, a autora analisou 4.523 comentários no YouTube aos vinte vídeos mais visualizados publicados por midiativistas naquele período, o que representa $10 \%$ do total de comentários desta amostra. Dentre os comentários analisados, verificou-se que apenas dez agregaram algum tipo de conteúdo ao vídeo apresentado. A autora verifica também que, dentre estes comentários, muito poucos atestaram a veracidade do vídeo a partir da presença do comentarista no local onde aquelas imagens foram produzidas ${ }^{20}$.

Quando a plataforma de análise é o Facebook, percebe-se uma convergência maior em torno do apoio à narrativa oferecida e, portanto, uma maior
16.INSTITUTO BRASILEIRO DE GEOGRAFIA E ESTATÍSTICA. Pesquisa Nacional por Amostra de Domicílios Contínua 2016: pesquisa suplemen$\operatorname{tar}$ TIC: acesso à internet e à televisão e posse de telefone móvel para uso pessoal. Rio de Janeiro: IBGE, 2016

17.VILLI, Mikko; MATIKAINEN, Janne. Participation in Social Media: Studying Explicit and Implicit Forms of Participation in Communicative Social Networks. Media and Communication, Lisboa, v. 4, n. 4, p. 109-117, 2016

18.SOUSA, op. cit.

19.CARPENTIER, Nico. Beyond the Ladder of Participation: An Analytical Toolkit for the Critical Analysis of Participatory Media Processes. Javnost -The Public, Abingdon, v. 23, n. 1, p. 70-88, 2016.

20.Sousa, op. cit., p. 234 
participação em termos da agregação de conteúdo. Tomando como base um dos vinte vídeos analisados, verificou-se que, dos 49 compartilhamentos aos quais a autora teve acesso, em 31 dos casos aquele que compartilhou o vídeo agregou algum tipo de conteúdo à narrativa ou, em outras palavras, houve algum tipo de reelaboração da narrativa ${ }^{21}$. Não obstante, o que se nota é que essas reelaborações propagaram informações dentro de uma mesma "bolha" - ou seja, falou-se mais ou menos a mesma coisa para pessoas que já pensavam mais ou menos da mesma forma.

Diante disso, nos perguntamos até que ponto o aumento da circulação da informação nas redes sociais é capaz de promover o diálogo entre divergentes, base para o convívio democrático? Ao contrário, nos parece que, munidas de informações sobre os mais diversos temas em espaços privados, as pessoas têm cada vez mais dificuldades em dialogar e tolerar visões distintas de suas crenças e orientações políticas. O contato com o divergente, que antes acontecia ao vivo e publicamente, hoje ocorre na internet, em ambientes privados, confortáveis para a troca de insultos, agressões e difamações. O espaço público para debate parece reduzido, não havendo convivência com a divergência, seja dentro - em razão dos limites das "bolhas" -, seja fora da internet. Portanto, as correntes de opiniões públicas são de difícil reconhecimento. Percebemos apenas fragmentos, dicotomias, narcisismo e produção de aparência (ou fachada ${ }^{22}$ ).

Ao lado disso, merece ser ressaltada a figura do "militante de internet". Este é aquele que confirma sua presença em todos os eventos, que curte, comenta e compartilha as postagens, que assina petições virtuais, mas que não participa presencialmente de quase nenhuma ação mais efetiva em torno das causas pelas quais afirma militar. Em outras palavras, a internet revela-se um espaço capaz de saciar o desejo de ver e ser visto, de integração e diferenciação social ${ }^{23}$. É importante a realização de mais pesquisas que quantifiquem e qualifiquem essas evidências.

Portanto, podemos afirmar que os caminhos abertos pela rede digital não passam tão perto da democracia. Pelo contrário, tudo indica que estamos diante de um aperfeiçoamento das sociedades punitivas ${ }^{24}$, baseadas no controle dos corpos e da subjetividade em prol da normatividade e da ordem pública, os quais favorecem a reprodução do sistema capitalista.

\section{CONSIDERAÇÕES FINAIS}

Podemos concluir que, assim como na comunicação comunitária ${ }^{25}$, no midiativismo a questão da sustentabilidade é também o ponto nevrálgico da reprodução e do funcionamento dos grupos. A falta de recursos inibe, dificulta e condiciona o cotidiano dos midiativistas que, com o agravamento de suas situações econômicas, muitas vezes paralisam ou reduzem suas atividades jornalísticas. Ao lado disso, a repressão policial e a consequente desmobilização social são outros aspectos que condicionam a continuidade do trabalho dos grupos; com as ruas vazias, 
estes perdem sua motivação principal: oferecer cobertura jornalística fidedigna aos atos políticos.

No que se refere ao funcionamento dos grupos, destacamos a sua atuação em rede como principal fundamento não só da sua organização, como também da proteção durante as ações e da multiplicação das mensagens e produtos gerados a partir de suas atividades. Dado o caráter voluntário do trabalho, conjugado com as atividades profissionais dos midiativistas, a gestão dos grupos é por "urgência", ou seja, quem está na hora toma as decisões e executa as ações necessárias. Esse modelo é oposto ao pressuposto da existência de líderes e foi capaz de confundir diversas vezes tanto as forças repressivas como a mídia. Diante da ausência de lideranças, tais instituições adotaram a estratégia de escolher aleatoriamente alguns deles para criminalizar, tal qual ocorreu no fantasioso processo que acusou 23 jovens de planejar um atentado na final da Copa do Mundo de 2014.

Ainda no que se refere ao funcionamento do midiativismo, apontamos também para as disputas entre os grupos a partir da diversidade de posições políticas ocupadas dentro daquilo que poderíamos qualificar como o campo político de esquerda no Brasil. Em parte reflexo de disputas partidárias, em parte de filosofias e crenças políticas distintas, tais disputas prejudicaram a unidade de algumas ações e dispersaram recursos que poderiam ter sidos reunidos na batalha que se travou contra os meios corporativos de comunicação, as forças repressivas do Estado e as elites conservadoras. Tais disputas e divergências serão exploradas com mais profundidade em um terceiro artigo que pretendemos escrever sobre a ideologia dos grupos de midiativismo no Rio de Janeiro.

Além da própria repressão do Estado, tantas vezes aqui assinalada, a atuação dos midiativistas teve como efeitos o enfraquecimento da legitimidade da mídia convencional e das forças repressivas. Tal atuação levou a uma mudança nos modos de atuar da mídia convencional, que se viu obrigada a noticiar certos fatos que não gostaria, retificar erros cometidos, ter mais cautela nas distorções que costuma operar e mudar sua linguagem, aproximando-se do registro documental utilizado na comunicação independente.

\section{REFERÊNCIAS BIBLIOGRÁFICAS}

CARPENTIER, Nico. Beyond the Ladder of Participation: An Analytical Toolkit for the Critical Analysis of Participatory Media Processes. Javnost - The Public, Abingdon, v. 23, n. 1, p. 70-88, 2016.

CASTELLS, Manuel. Redes de indignação e esperança: movimentos sociais na era da internet. Tradução de Carlos Alberto Medeiros. Rio de Janeiro: Zahar, 2013.

ELIAS, Norbert.Escritoseensaios: 1.Estado, processo,opiniãopública.Organizado por Federico Neiburg; Leopoldo Waizbort. Rio de Janeiro: Zahar, 2006. 
comunicação \& educação • Ano XXV • número 1 • jan/jun 2020

FOUCAULT, Michel. Vigiar e Punir. 23. ed. Petrópolis: Vozes, 2000.

GOFFMAN, Erving. A representação do eu na vida cotidiana. Tradução de Maria Célia Santos Raposo. Petrópolis: Vozes, 1985.

INSTITUTO BRASILEIRO DE GEOGRAFIA E ESTATÍSTICA. Pesquisa Nacional por Amostra de Domicílios Contínua 2016: pesquisa suplementar TIC: acesso à internet e à televisão e posse de telefone móvel para uso pessoal. Rio de Janeiro: IBGE, 2016.

JENKINS, Henry. Cultura da Convergência. São Paulo: Aleph, 2008.

LÉVY, Pierre. Cibercultura. São Paulo: Editora 34, 1999.

MACEDO, Marcelo Ernandez. Zé Pureza: etnografia de um acampamento no norte Fluminense. 2003. Tese (Doutorado em Ciências Sociais) - Universidade Estadual do Rio de Janeiro, Rio de Janeiro, 2003.

MACEDO, Marcelo Ernandez; SEIDEL, A.; FERREIRA, M. O Jornal O Cidadão e os desafios para a sustentabilidade de veículos de comunicação comunitária. Comunicação \& Política, Porto Alegre, v. 31, p. 134-151, 2013.

MACEDO, Marcelo Ernandez; SILVA, Flávio; CARDOSO, Alessandra. A formação de grupos de midiativismo no Rio de Janeiro. ALCEU, Rio de Janeiro, v.18, n.35, p.94-113, jul./dez. 2017.

SIMMEL, Georg. On individuality and social forms. Chicago: University of Chicago Press, 1971.

SOUSA, Ana Lucia Nunes de. De La Calle A La Red: Videoactvismo En El Contexto De Las Protestas En Contra Del Mundial De Fútbol En Rio De Janeiro (2014). 2017. Tese (Doutorado em Ciências da Comunicação e Jornalismo) Universidad Autónoma de Barcelona, Barcelona, 2017.

VILLI, Mikko; MATIKAINEN, Janne. Participation in Social Media: Studying Explicit and Implicit Forms of Participation in Communicative Social Networks. Media and Communication, Lisboa, v. 4, n. 4, p. 109-117, 2016. 